\title{
The italian magnetic repeat station network: results from the 2012.5 'Reduced network' completion
}

\author{
Guido Dominici ${ }^{1,{ }^{\star}}$, Antonio Meloni ${ }^{1}$ \\ ${ }^{1}$ Istituto Nazionale di Geofisica e Vulcanologia, Rome, Italy
}

\author{
Article history \\ Received October 26, 2016; accepted December 7, 2016. \\ Subject classification: \\ Earth's magnetic field, Geomagnetic map, Magnetic surveys, Magnetic repeat stations, Secular variation, Global and regional models
}

\begin{abstract}
In Italy INGV (Istituto Nazionale di Geofisica e Vulcanologia) has systematically undertaken the task of making periodic measurements of the Earth's magnetic field on a network of more than 110 points (repeat stations), with an average spacing around $55-60 \mathrm{~km}$. Measurements are repeated regularly every 5 years and the last published data reports and magnetic maps, refer to 2010.0, are available in Dominici et al, 2012. At that time the report referred to a survey of 131 repeat stations (including 2 observatories, 11 stations in Albania, 3 stations in Corsica and 1 in Malta) carried out between 2009 and 2010, also with the purpose of updating the national magnetic cartography. At the epoch 2012.5 a selection of stations, from the first order Italian Magnetic Network, selected on the basis of the lowest amplitude values of anomaly with respect to a 'normal' field, was repeated. The number of the selected stations amounts to 25 , distributed according to an almost uniform national geographical coverage, with an average spacing around $100 \mathrm{~km}$. Secular variation and analytical expressions, such as second order polynomials, in latitude and longitude for all field elements, were determined and coefficients were obtained for the spatial field variation and secular variation. We describe here the characteristics of this reduced network with the data elaboration procedure, normal fields and maps, and compare the results with other magnetic field models
\end{abstract}

\section{Introduction}

Magnetic surveys are normally undertaken for magnetic maps compilation, and associated data elaborations: in particular for main field and magnetic anomalies representation, for observation of geomagnetic field elements secular variation and for the computation of regional magnetic models. All surveys are based on two typical magnetic networks, usually called first order (repeat stations) and second order. Repeat stations are devoted to main field representation; they are constituted of accurately located points at the Earth's surface, where the three components of the geomagnetic field are regularly measured to the highest possible accuracy [see for example: Newitt et al. 1996, Lanza and Meloni 2006]. Regional magnetic models, also called normal fields, [see Haines et al. 1990] are computed on the basis of repeat stations to represent the main geomagnetic field elements pattern over a certain area. Second order networks are denser measurement point networks that are generally finalized to improve crustal magnetic anomalies representation.

The magnetic characteristics of the Italian territory have been the subject of several investigations. A brief history of Italian magnetic surveys dates back to the seventeenth century and includes the first survey made in 1640, when Declination (D) was measured over 21 stations by Fathers Borri and Martini. In more recent times the magnetic survey of 1881-1892 by Chistoni and Palazzo can be considered the first 'modern' 3-component national magnetic survey in the unified kingdom of Italy. At that time D, I (Inclination) and $\mathrm{H}$ (Horizontal Intensity) were measured on 284 stations by the Ufficio Centrale di Meteorologia e Geodinamica (UCMG). More detailed information on this and older magnetic measurement compilations, can be found in Cafarella et al. [1992a], [1992b].

For what concerns recent magnetic networks in Italy a fundamental starting point was the 1979.0 survey. In that occasion a repeat station network of about 120 data points was assessed [Molina et al. 1985] and moreover a full second order magnetic data network, with a higher spatial density of measurements, was deployed. This last one consists of horizontal intensity $(H)$, vertical intensity $(Z)$ and total field (F), with measurements taken in the period 1977-1981 on 2552 stations within the framework of the Finalized Project Geodinamica (PFG-CNR), see Molina et al. [1985].

The 1979.0 network (all above mentioned measurements were reduced to this central epoch) has ge- 
nerated a full representation of magnetic elements, a magnetic maps compilation and a set of coefficients for normal field regional models to represent the main magnetic field elements pattern over Italy.

For what concerns Declination, this was measured over 1529 points and measurements were, undertaken in the 30s of nineteen hundred by the Military Geographical Institute (IGM), for military demands. This set of declination measurements were successively updated for a publication released in 1973.0. Information on this network can be found in Talamo [1975].

In later years national magnetic surveys were all dedicated to the repetition of the first order network of about 120 repeat stations including 2 Observatories. From 1994 onwards surveys also included 11 stations in Albania, from 20053 stations in Corsica and from 2010 1 in Malta, as shown in Figure 1 that reports situation at 2010.0. The main goal of these studies was the determination of secular variation and consequently the main field generated in the Earth's core. These most recent surveys have been described in Meloni et al. [1988, 1994], Coticchia et al. [2001] and for the years after 2005.0 Dominici et al. [2007, 2012], that can be considered the latest surveys at the national level. All magnetic stations, constituting the so-called second order network, have been used since then, only updated on the basis of the first order network (repeat stations) results in order to bring up to date the magnetic cartography. This was done for all the latest years at 2000.0, 2005.0, 2010.0. [De

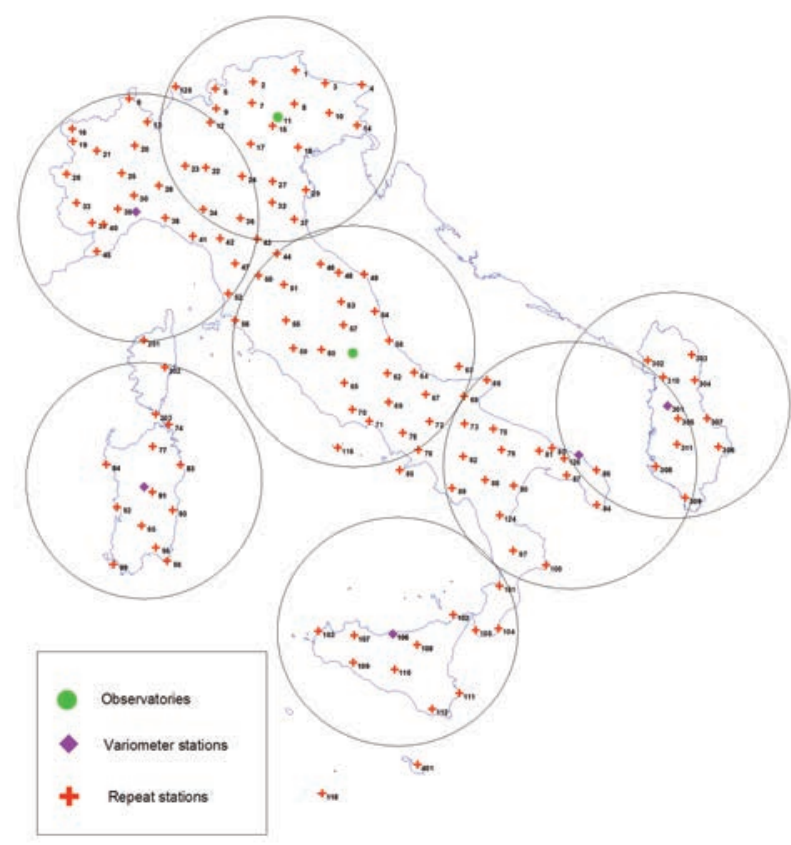

Figure 1. The original location of 131 repeat stations in Italy including 2 Observatories. The latest full survey undertaken at 2010.0 also included 11 stations in Albania, 3 stations in Corsica and 1 in Malta. Circles indicate Observatory and variometric station areas of influence.
Santis et al. 2003, Dominici et al. 2012].

If we compare Italian repeat station density (an average of 1 station over $3000 \mathrm{~km}^{2}$ ) with similar European magnetic networks, we find that other nations usually rely on a sensibly smaller density of repeat stations. For example France relies on about 1 station over 20,000 km² [Mandea 2004], Spain on 1 station over $12,500 \mathrm{~km}^{2}$. Several workshops in the European magnetic operators community were convened to discuss problems regarding magnetic measurements, in order to exchange experiences and coordinate the individual efforts, and also to discuss what measurements density would be considered optimal for a national undertaking. One successful initiative at the European level is known as MagNetE (Magnetic Network of Europe) and was supported by a resolution of IAGA (International Association of Geomagnetism and Aeronomy). MagNetE workshops were organised every two years, in order to ensure continued cooperation between the participants from about 20 European countries. The latest workshops were held in May 2011 in Rome, in Prague in 2013 and in Budapest in 2015.

In this paper we present the results of a recent magnetic survey undertaken in 2011-2012 on a selection of the above mentioned repeat stations of the first order Italian Magnetic Network. The number of these selected stations amounts to 25 , compared to the about 120 stations typically measured in the last 40 years or so. In the next paragraphs we will describe this 'reduced' network, how points were selected, results of the measurements, and we will discuss advantages and disadvantages of this reduced density magnetic network.

\section{Magnetic repeat station distribution on a 'reduced' network}

Geomagnetic repeat station surveys are mainly devoted to secular variation knowledge (from the short time scale 2-5 years onwards) and the understanding of its pattern over the interested area, usually starting with the national area. With this information available, local magnetic models and magnetic maps can be updated.

The average distance of magnetic stations, the time interval for their reoccupation and all the procedures needed for a full measurement of magnetic field elements, are the basis of the Newitt et al report [Newitt et al. 1996] where all details for magnetic repeat stations surveys are described. This report and subsequent discussions and agreements, have brought to the suggestion that an average distance between stations of $125 \mathrm{~km}$ and a 2 year time interval for reoccupation, are considered satisfactory in almost all ca- 
ses; these parameters are also considered to be a good compromise between costs related to the survey operations and value of the results. The same would also be true if we consider the survey results accuracy. In fact a good survey should not be completed in a too long time window, since secular variation keeps going on during the whole effort. It must be considered that the time window should be kept as short as possible in order to make minimum correction for secular variation; furthermore scientific institutions generally can rely only on one or two teams in the field, so one year total measurement time is considered acceptable.

In the 'reduced' network described here we started taking in consideration that first order magnetic surveys must rely on stations whose magnetic elements, once measured, should report the magnetic value representative of the main field for that determined region. This is because magnetic measurements provide not only a measurement of the earth's core field (at large the main field) but also an insight into the magnetic structure of the Earth's crust, that is closely connected to its geological structure. For this reason the station selection should be done in order to include only stations representative of the main field. The need to cover almost uniformly all the national area was also a constrain. Following above said criteria at the end the number of the selected stations amounts to 25 , distributed according to a national geographical coverage, with an average spacing around $100 \mathrm{~km}$ (Figure 2). For what concerns field instrumentations, also in 2012.5 survey a DIM (Declination Inclination Magnetometer) a portable theodolite fitted with a fluxgate magnetometer, was used for the angular measurements of the Earth's magnetic field (therefore declination D and inclination I, with 0.1 minute of arc accuracy) and a proton precession magnetometer for the measurement of the field intensity F ( $0.01 \mathrm{nT}$ accuracy). All other magnetic elements can be derived. Survey was repeated on known repeat stations and in the general case azimuth were already determined and known. However in a few cases, stations could not be reoccupied (i.e. a station mark was lost) and a new mark was manufactured onsite. In these cases azimuth determination was made anew; this was also done on those stations in which the visibility of the old azimuth marks was limited or absent. A gyroscopic theodolite was used in all these cases. This instrument was preferred to Global Positioning System (GPS) instruments because it can also be used for measurements in tunnels or roof covered places. Moreover even where, in presence of bushes of tall stem, GPS could show problems for the satellites limited visibility. In addition the two instruments show comparable precisions of tenth of minutes.

For each repeat station a monograph is realized. In the monograph the site is described, instructions are given to easily reach it, what land marks are useful for the approach, what azimuths are visible and all information that could be useful for identification.

\section{Magnetic measurement reduction procedures, normal fields and maps}

Magnetic elements observed at the repeat stations are reduced firstly to 02 UT using diurnal variation correction from digital data obtained at magnetic observatories working at the time of measurements in the field. For what concerns the 2012.5 survey these were Duronia (Dur) and Castello Tesino Observatory (Cts). Portable variometric stations were also used for rapid magnetic variation corrections, when stations were considered far away from the two indicated Observatories; in this case a portable time variation fluxgate station was installed (all variometric stations are reported in Figure 2).

The value of a generic element $\mathrm{E}$ (i.e., D,I or F)

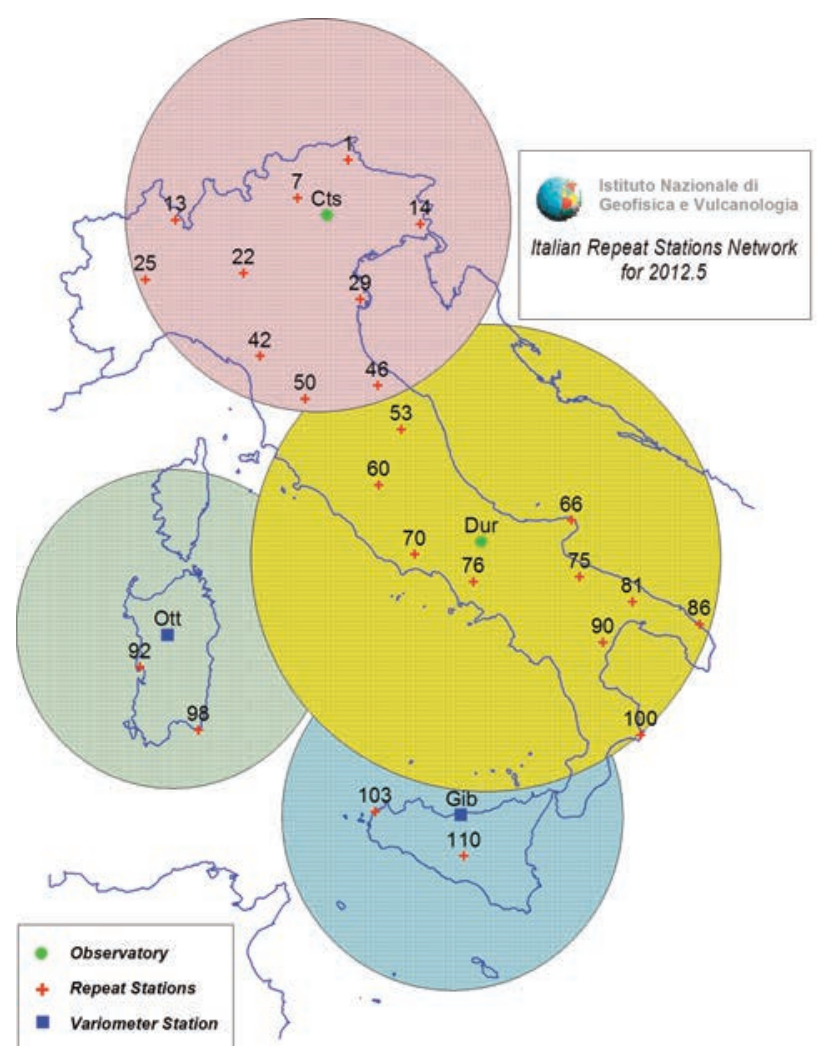

Figure 2. The geographical distribution of the 25 reduced network stations as described in this paper for the 2012.5 reduced network. Colored circles indicate Observatory and variometric station areas of influence. Pink refers to CTS Observatory area of influence: Yellow refers to DUR Observatory area of influence. Green refers to Variometric OTT station area of influence; Light blue refers to Variometric GIB station area of influence. In case of overlapping regions the two variometric records were considered. 
at station s, i.e. reduced, at 02UT was calculated following the:

$$
E_{s}\left(02_{U T}\right)_{d}=E_{v a r}\left(02_{U T}\right)_{d}+\left[E_{s}(t)_{d}-E_{v a r}(t)_{d}\right]
$$

Where:

$E_{s}\left(02_{U T}\right)_{d}=$ Value of element $E$ at station $s$ reduced at time $02_{U T}$ of day of measure $d$

$E_{\text {var }}\left(02_{U T}\right)_{d}=$ Value of element $E$ at variometer station $s$ at time $02_{U T}$ of day of measure $d$

$E_{s}(t)_{d}=$ Value of element $E$ observed at station $s$ at time $t$ at that day $d$

$E_{v a r}(t)_{d}=$ Value of element $E$ at variometer station at time $t$ at that day $d$

Secondly data are reduced to Castello Tesino Obs. for the fixed epoch, i.e. 2012.5 following the:

$$
E_{s}(2012.5)=E_{o b s}(2012.5)+\left[E_{s}\left(02_{U T}\right)_{d}-E_{o b s}\left(02_{U T}\right)_{d}\right]
$$

Where:

$E_{s}(2012.5)=$ Value of element $E$ at station $s$ reduced at epoch 2012.5

$E_{\text {obs }}(2012.5)=$ Mean Value of element $E$ at Observatory at epoch 2012.5

$E_{o b s}\left(02_{U T}\right)_{d}=$ Value of element $E$ measured at Observatory at time $02_{U T}$ of day of measurement $d$.

The classical technique of SHA (Spherical Harmonic Analysis) represents mathematically the configuration of the Earth's magnetic field in terms of spherical harmonics. This can be applied only to the entire Earth's globe and the characteristic minimum wavelength associated with this technique, used for example in IGRF (International Geomagnetic Reference Field), when maximum degree is 12 , is around $4000 \mathrm{~km}$ [IAGA 2010]. This is the reason why, on a limited part of the globe, regional magnetic models are normally used. In the Italian area different techniques were used during the years. In many cases simple polynomial second order, together with other methods, for example SCHA (Spherical Cap Harmonic Analysis) see De Santis et al. 1997, and other related techniques, were applied at the local scale.

In this paper a regional magnetic model was constructed using a mathematical second order polynomial, that we call 'normal field'. At the scale of the case here discussed we expect that the normal field includes almost all the contribution from the Earth's core (equivalent to a SHA with maximum degree 12-14). However it cannot be excluded that a deep lithospheric contribution could be involved and represented in the normal field coefficients [see also Korte and Lusur 2012]. The normal field was computed independently for each element and results, for a generic element $\mathrm{E}$, from the expression:

$$
E(\phi, \lambda)=a_{0}+a_{1} \phi+a_{2} \lambda+a_{3} \phi^{2}+a_{5} \phi \lambda
$$

$\phi$ and $\lambda$ are latitude and longitude respectively and $a_{i}$ are the coefficients. These coefficients were computed by means of a least squares fit over the observational values. When the total number of repeat stations was used, as for all latest surveys (for example 2010.0, 2005.0, etc...) in order to avoid contamination from stations located in anomalous areas, the Chauvenet rejection criterion was generally used for removing anomalous values from the computation of the least squares fit coefficients. Essentially the mean residual of each individual station was calculated using the expression $\sigma= \pm \sqrt{[v v] /(n-6)}$ where $[v v]$ is the sum of the square differences between observed and computed values, $n$ is the number of stations used in the inversion and 6 is the number of coefficients. Stations with residuals greater than $2 \sigma$ were neglected and the calculation repeated for the remainder. This

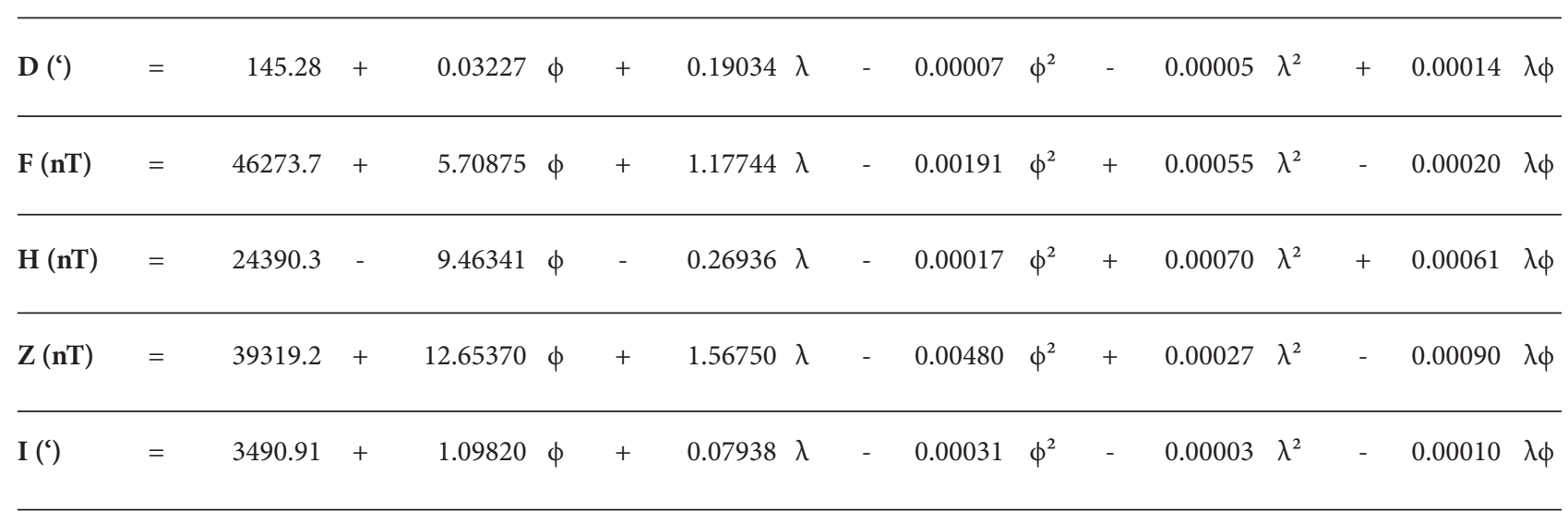

Table 1. Coefficients of the normal geomagnetic field in Italy for $2012.5 ; \phi=\left(\right.$ Lat. $\left.-42^{\circ}\right)$ in minutes $\lambda=\left(\right.$ Long. $\left.-12^{\circ}\right)$ in minutes $\mathrm{D}$, I in minutes $\mathrm{F}, \mathrm{H}, \mathrm{Z}$ in $\mathrm{nT}$ 

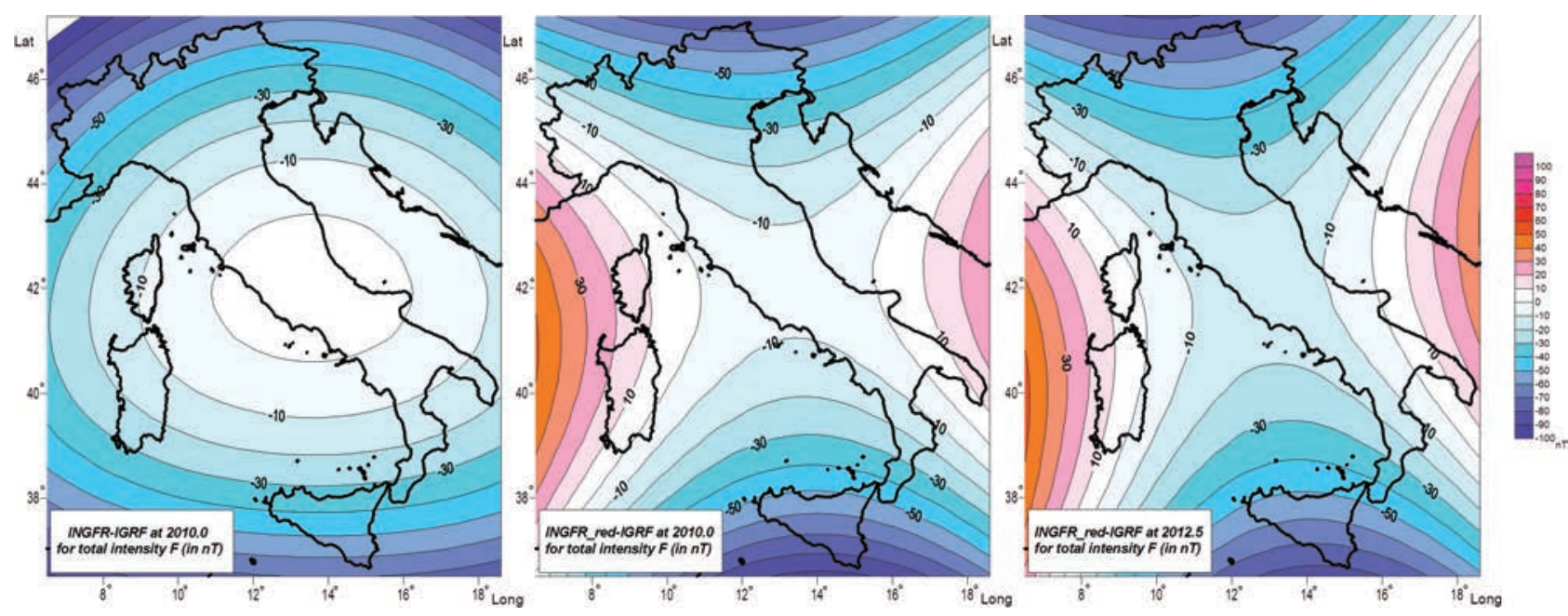

Figure 3. At 2010.0 Difference represented with a colour scale between F normal field polynomial interpolation from INGRF on all standard repeat stations, and 2010.0 F from IGRF (panel a). At 2010.0 F normal field polynomial interpolation INGRF_red computed on only 25 stations that were selected later for the 2012.5 survey and IGRF (panel b). Finally In panel c the comparison made at 2012.5 between IGRF and INGRF_red from 2012.5 measurements.

procedure was repeated until no residuals greater than $2 \sigma$ were left. For the 2010.0 survey the stations neglected and the mean residual $\sigma$ for all the remaining stations were 39 and $\sigma=2.535$ ' for $\mathrm{D}, 31$ stations and $\sigma=25.1 \mathrm{nT}$ for $\mathrm{F}, 25$ stations and $\sigma=22.18 \mathrm{nT}$ for $\mathrm{H}$, 28 stations and $\sigma=27 . \ln \mathrm{T}$ for $\mathrm{Z}$. In the case of the reduced network (at 2012.5), reported in this paper, this criterion was not applied. This point was taken in consideration since the Chauvenet criterion is a means of assessing whether one experimental data (an outlier) from a set of observations, is likely to be spurious; we considered that this should not be applied on an objectively more limited data set. It was considered that deletion of outlier data should not be done especially in small sets where a normal distribution cannot be assumed. Coefficients of the normal geomagnetic field in Italy for 2012.5 are reported in Table 1.

In order to test the validity of a reduced network approach, at least in the case of the Italian area, we made a comparison of the normal polynomial field interpolation, called here INGRF with the IGRF for total intensity F. These comparisons are reported in Figure 3. For this test we had first compared the normal field for the epoch 2010 (INGRF), when all repeat stations were available (panel a) and afterwards using only the 25 stations (INGRF_red), that were successively used for the 2012.5 reduced network (panel b), both models were compared to IGRF. For the same epoch (2010.0) we found that the use of a limited number of stations (that were afterwards used for the reduced network) had not introduced sensibly larger differences with respect to the use of the full set of available repeat stations data. In panel $\mathrm{c}$ the only available 25 reduced network station were used for a new polynomial normal field (INGRF_red) at 2012.5. This last panel shows almost same patterns with respect to IGRF 2012.5 similarly to the 2010.0 case. All panels show larger differences at the edges and better agreements at the center of the considered areas. This effect can be interpreted as a larger ability of polynomial models to represent the earth's core field at the map's center than at the edges. We conclude that a comparison of the two 2010.0 models, obtained from the original and reduced networks, shows a moderate difference across all the Italian area.

\section{Conclusions}

In this paper we presented the results of a magnetic survey undertaken in 2012 on a selection of the Italian network of magnetic repeat stations (first order network). The original number of stations for the previous full 2010 survey was 131 including 2 Observatories including 11 stations in Albania, 3 stations in Corsica and 1 in Malta, as shown in Figure 1. From this network some stations were selected for the 2012.5 that was designed as a 'reduced' survey. We have described how the reduced network stations were chosen and we stressed that all reduced network points were selected on the basis of their minimum deviation from the expected earth's core magnetic field, and considering the geographical distribution in order to cover uniformly almost all the Italian area. At the end the number of selected stations amounts to 25 , distributed over the Italian area with an average spacing around $100 \mathrm{~km}$ (Figure 2).

Regional modeling of magnetic data from a repe- 
at station network was also the mathematical technique used in the case of this reduced network at 2012.5, in order to represent the main field (essentially the core field) as accurately as possible at the local scale.

In this study we used only simple polynomials that were considered to give an adequate amount of information to represent the main field. An empirical rule given by Bullard [1967] relates the number of coefficients of a global SH model with the minimum wavelength that a global model can represent and gives the details represented by the regional model. According to Bullard's rule such relation brings to a minimum wavelength of about $800 \mathrm{~km}$ for the second order degree polynomial representation for the area here considered. In Figure 3 all comparisons have shown that the use of a limited number of stations (that were afterwards used for the reduced network) had not introduced sensibly larger differences with respect to the use of the full set of available repeat stations data when compared to IGRF.

\section{References}

Bullard, E.C. (1967): The removal of trend from magnetic surveys, Earth Planet. Sci. Lett., 2, 293-300.

Coticchia, A., A. De Santis, A. Di Ponzio, G.Dominici, A.Meloni, M. Pierozzi, M. Sperti, (2001) La Rete Magnetica italiana e la Carta Magnetica d'Italia al 2000.0, Bollettino di Geodesia e Scienze affini, 4, 261-291.

Cafarella, L., A. De Santis and A. Meloni (1992a): Secular variation from historical geomagnetic field measurements, Phys. Earth Planet. Inter., 73, 206-221.

Cafarella, L., A. De Santis and A. Meloni (1992b): Il Catalogo geomagnetico storico italiano, Pubblicazioni dell'Istituto Nazionale di Geofisica vol. 7, 160 pp.

De Santis, A., M. Chiappini, G. Dominici e A. Meloni (1997): Regional geomagnetic field modelling: the contribution of the Istituto Nazionale di Geofisica, Annali di Geofisica, XL, 5, 1161-1169.

De Santis, A., L. Gaya-Piqué, G. Dominici, A. Meloni, J.M. Torta, and R. Tozzi (2003): ITalian Geomagnetic Reference Field ITGRF: update for 2000 and secular variation model up to 2005 by autoregressive forecasting, Annals of Geophysics, 46, 3, 491-500.

Dominici, G., A. Meloni, M. Miconi, M. Pierozzi and M. Sperti (2007): La Rete Magnetica Italiana e la Carta Magnetica d'Italia al 2005.0, Bollettino di Geodesia e Scienze affini,1,1-47.

Dominici, G., A. Meloni, A. Di Ponzio, M. Miconi (2012): Italian Magnetic Network and magnetic reference fields at 2010.0, Annals of Geophysics, 55, 6, doi: $10.4401 /$ ag-5411.
Haines, G.V. (1990): Regional magnetic field modelling: a review, J. Geomag. Geoel.,42, 1001-1018.

IAGA (International Association of Geomagnetism and Aeronomy) Working Group V-MOD (2010): International Geomagnetic Reference Field: the eleventh generation, Geophysical Journal International, 183, 1216-1230.

Korte, M. and V. Lesur (2012): Repeat station data compared to a global geomagnetic field model, Annals of Geophysics, 55, 1101-1111.

Lanza, R., and A. Meloni (2006): The Earth’s Magnetism: An Introduction for Geologists, Springer, 290 pp.

Mandea, M. (2004): Reseau magnétique de répétition de la France 2002, Bureau Central de Magnetisme terrestre, Paris, Bullettin n. 20.

Meloni, A., O. Battelli, G. Dominici, S. Arca and A. Marchetta (1988): Italian magnetic network at 1985.0, Bollettino di Geodesia e Scienze Affini, 4, 339-350.

Meloni, A., Battelli, O., De Santis, A. and Dominici, G. (1994): The 1990.0 magnetic repeat station survey and normal reference fields for Italy, Annali di Geofisica, Vol. XXXVII, N. 5, 949-967.

Molina, F., E. Armando, R. Balia, O. Battelli, E. Bozzo, G. Budetta, G. Caneva, M. Ciminale, N. De Florentiis, A. De Santis, G. Dominici, M. Donnaloia, A. Elena, V. Iliceto, R. Lanza, M. Loddo, A. Meloni, E. Pinna, G. Santarato, R. Zambrano (1985): Geomagnetic Survey of Italy. Repeat Stations Network and Magnetic Maps: a Short Report, Annales Geophysicae, 3 (3), 365-368.

Newitt, L.R., Barton C.E. and J. Bitterly (1996): Guide for magnetic repeat station surveys, IAGA Working Group, 115.

Shepard, D. (1968): A two-dimensional interpolation function for irregularly-spaced data, In: Proceedings $23^{\text {rd }}$ National Conference ACM, ACM, 517-524.

Talamo R (1975): Le carte magnetiche d'Italia delle isodinamiche della $\mathrm{H}$ e delle isogone dell'Istituto Militare e loro aggiornamento al 1973.0, Bollettino di Geodesia e Scienze Affini, Vol. XXXIV, n.1,p.34.

\footnotetext{
^Corresponding author: Guido Dominici Istituto Nazionale di Geofisica e Vulcanologia, Roma, Italy; tel. +39-6-51860312 - fax +39-6-51860397 email: guido.dominici@ingv.it 2017 by Istituto Nazionale di Geofisica e Vulcanologia. All rights reserved
} 